\title{
PREOPERATIVE BLOOD DONATION PROGRAM AND POSTOPERATIVE LOW MOLECULAR WEIGHT HEPARINE (LMWH) PROPHYLAXIS IN PATIENTS UNDERGOING RADICAL PROSTATECTOMY
}

\author{
Marco Grasso, Silvia Confalonieri, Salvatore Blanco, Angelica Grasso and Sogni Angelo'.
}

Department of Urology and Department of Anesthesiology'. Desio Hospital. Desio. Milan. Italy.

Summary.- OBJECTIVES: The need and timing of perioperative heparin prophylaxis is matter of debate. The aim of our work is to review the incidence of venous thromboembolism (VTE) after radical retro pubic prostatectomy (RRP) in patients undergoing preoperative blood donation, compressive stockings, haemodilution, surgical prevention of lymphocoele and postoperative low molecular weight heparin therapy as prophylaxis for thrombotic events.

METHODS: This is a retrospective analysis considering a series of 500 RRP performed between 1999 and 2006 by the same Surgeon (MG) at the Urological Unit, Desio Hospital, Milan, Italy.

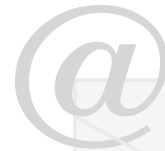

CORRESPONDENCE

Marco Grasso

San Gerardo Hospital

Via Pergolesi, 33

20052 Monza. Milano. (ltaly).

grasso.m@virgilio.it

Accepted for publication: May $8^{\text {th }}, 2008$.
All the patients were enrolled in an auto transfusion program and were subjected to autologous blood donation. Low molecular weight heparin $10.4 \mathrm{ml}$ of Calcic $\mathrm{Na}$ droparin 3800 UI s.c. daily) was administrated within 24 hours following surgery until the 11 th postoperative. Age, PSA, basal, preoperative and postoperative haemoglobin values were assessed in each patient. The incidence of venous thromboembolism was calculated taking into consideration occurrences of both pulmonary embolism and deep venous thrombosis.

RESULTS: In this retrospective analysis we did not observe any major event including intra- or peri-operative deaths. There was one occurrence of pulmonary microembolism and one sural phlebitis that were treated with prolonged heparin and dicumarol therapy.

Two significant haemorrhagic events occurred in the postoperative period requiring surgical revision.

CONCLUSIONS: These data suggest that low weight heparin prophylaxis starting within 24 hours following radical prostatectomy, associated with preoperative blood donation, intra-operative haemodilution, compression stockings, surgical care to avoid lymphocoele and early mobilization is effective in preventing venous thromboembolism.

Keywords: Radical prostatectomy. Heparin. Bleeding. Venous thromboembolism.

Resumen.- OBJETIVO: La necesidad y el tiempo de la profilaxis perioperatoria con heparina es una cuestión discutida. El objetivo de este trabajo es revisar la incidencia de tromboembolismo venoso después de prostatectomía retropúbica en pacientes sometidos a donación de sangre preoperatoria, sistemas compren- 
sivos intermitentes, hemodilucion, prevención quirúrgica del linfocele y terapia postoperatoria con heparina de bajo peso molecular como profilaxis para los eventos trombóticos.

MÉTODOS: Análisis retrospectivo considerando una serie de 500 prostatectomías radicales retropúbicas realizadas entre 1999 y 2006 por el mismo cirujano (MG) en la unidad de urología del Hospital Desio de Milán, Italia. Todos los pacientes fueron enrolados en un programa de autotrasfusión y sometidos a donaciones sanguíneas autólogas. Se administró heparina de bajo peso molecular (Nandroparina cálcica 3800 UI subcutaneas al díal dentro de las 24 horas posteriores a la cirugía y hasta el décimoprimer día posoperatorio. La edad, el PSA, la hemoglobina basal, preoperatoria y postoperatoria fueron evaluados en cada paciente. La incidencia de tromboembolismo venoso fue calculada teniendo en consideración la aparición de embolismo pulmonar y trombosis venosa profunda.

RESULTADOS: En este análisis retrospectivo no observamos ningún evento importante incluyendo muertes intra o perioperatorias. Hubo un caso de microembolismo pulmonar y otro de flebitis sural que fueron tratados con heparina y dicumarol a largo plazo.

Hubo dos eventos hemorrágicos significativos en el periodo posoperatorio que requirieron resección quirúrgica.

CONCLUSIONES: Estos datos sugieren que la profilaxis con heparina de bajo peso molecular iniciada dentro de las primeras 24 horas después de la prostatectomías radical, asociada con donación de sangre preoperatoria, hemodilucion intraoperatoria, dispositivos de compresión intermitente, cuidado quirúrgico para evitar linfocele, inmovilización precoz es eficaz previniendo el tromboembolismo venoso.

Palabras clave: Prostatectomía radical. Heparina Sangrado. Tromboembolismo venoso.

\section{INTRODUCTION}

Venous thromboembolism (VTE) is a common complication of surgical procedures. The risk of VTE in surgical patients is determined by a combination of individual predisposing factors and the type of surgery. Advanced age, obesity, malignancy, intra operative lithotomy position and pelvic surgery with or without lymph node dissection are established risk factors of VTE; however, patients undergoing RRP suffer increased risk of VTE (1).
Prophylaxis with mechanical and pharmacological methods has been shown to be effective and safe for most types of surgery. However, the use of peri-operative Low Molecular Weight Heparin $(\mathrm{LMWH})$ may increase the risk for bleeding (2).

RRP, which is one of the most common oncological procedures in urological surgery, is classified as a high risk procedure for VTE by the American College of Chest Physicians. It is estimated that 1-5\% of patients undergoing major surgery has a symptomatic VTE. Risk of an associated fatal pulmonary embolism (PE) is estimated to be less than $0.25 \%$. Most American urological surgeons agree that early mobilization associated to compressive stockings (3) and the other physical devices are critical and sufficient in preventing VTE without need of pre- or intraoperative anti-coagulation. However, anticoagulation represents standard treatment in Europe and the lowdose unfractionated heparin or low-molecular-weightheparin (LMWH) are the option of choice even at the cost of increasing the risk of bleeding. Therefore, the necessity of heparin prophylaxis in RRP and its timing remains a matter of debate.

In Europe, heparin prophylaxis is performed pre-operatively to improve effectiveness (4), while post-operative prophylaxis or no treatment at all is performed in North America practice to improve safety. tively:

The aim of this study is to consider, retrospec-

1) The incidence of VTE in patients undergoing RRP who were subjected to auto-transfusion, haemodilution, early mobilization, compressive stockings and post-operative administration of $\mathrm{LMWH}$;

2) Post-operative blood transfusion rate.

\section{MATERIALS AND METHODS}

In this retrospective study, we assessed the incidence of VTE in a series of 500 patients (mean age 65 years) treated with Retro-pubic Radical Prostatectomy (RRP) for clinically localized disease. All the surgical procedures were performed under general anaesthesia between 1999 and 2006 by the same surgeon (MG, Department Chief). Clinical signs, laboratory parameters and percentage of auto-transfusions were considered. In addition, we analysed age, PSA, basal, pre-operative, pre-transfusion and post-operative haemoglobin levels and the number of transfusions received by each patient. 
Incidence of venous thrombo-embolism included occurrences of pulmonary embolism and deep venous thrombosis.

\section{1) PREOPERATIVE APPROACH}

\section{Preoperative autologous donation program $(5,6)$.}

All the patients were enrolled in a preoperative autologous donation program. Preoperative autologous blood donation (PABD) is the most frequent autotransfusion procedure performed in elective surgery because of its great appeal with patients and surgeons (7). Pre-depositing was performed by collecting one or more units of blood 30-40 days before surgery, depending upon patient's clinical conditions lage, weight, basal haemoglobin, co-existing disease) and carried out 15-20 days before surgery. Blood is collected into a single pack with CDP-A 1 anticoagulant (8).

Most frequently two autologous blood units were collected from each patient.

All the patients were screened for viral infections. Blood from patients testing positive for HIV, $\mathrm{HBV}$ and HCV was excluded.

Patients suffering from the following conditions were not suitable for autologous blood donation: infection at the time of donations; present or past history of epilepsy; unstable angina; cardiovascular accident, significant cardiac or pulmonary disease, uncontrolled hypertension.

\section{Patients who need infusions of predeposited autolo- gous units.}

Blood haemoglobin values were checked after surgical removal of the prostate and control of bleeding.

Clinical conditions eligible for intra-operative transfusion of autologous blood included:

- History of severe cardio-respiratory problems.

- Well compensate coronary disease with $\mathrm{Hb}$ below $10 \mathrm{~g} / \mathrm{dl}$ or hematocrit less than $30-33 \%$ at the intraoperative control.

- Intra-operative haemorrhage accompanied by unstable heamodynamic parameters.

One litre of saline infusion was administrated in the peri-operative period to reach optimal rheolo- gic conditions (Haemoglobin value around $10 \mathrm{~g} / \mathrm{dl}$ and hematocrit about 30\%).

\section{Compressive stocking}

To prevent intra-operative venous vasodilatation which can reduce blood flow, causing blood stasis, and potentially can provoke endothelial distension beyond the tunica media with consequent damage to the tunica intima, compressive measures were adopted. The risk of thrombo-embolism is further increased in the presence of blood stasis by activate platelets, coagulation factors and other thromobogenic products caused by surgical trauma and postoperative immobilization. Therefore, all patients received compressive stocking made of poliamide $(75 \%)$ and elastam (25\%), with decreasing compression from the popliteal fossa to the feet. It was tailored for each patient' size and worn two hours before the operation till complete mobilization.

\section{2) SURGERY}

The patient was placed in supine, avoiding prolonged lithotomy position believed to increase the risk of thromboembolism (9), under general anaesthesia. The surgical procedure was performed as a modified Radical Retro-pubic Prostatectomy according to Walsh (10). Of particular importance and carefully sought was the clipping of lymphatic vessels during lymphadenectomy to minimize the incidence of lymphocele since the mechanical compression caused by lymph collection around the iliac vessels is believed to increase the risk of thrombotic events. Two abdominal drainages and transurethral catheter were left at the end of the procedure (11).

Within the first post-operative month, patients received an abdominal and pelvic ultrasound for follow up.

\section{3) POST-OPERATIVE PERIOD}

\section{Early mobilization and Postoperative care}

Peri-operative care was performed in the recovery room with infusion of electrolytic and glucosalin solutions as needed.

Post-operative infusion therapy was administrated until the 3rd day following surgery to support circulation unless otherwise indicated; two litres of electrolytic solution were given every 24 hours while gradually starting feeding from the 1 st postoperative day. 
For each patient, low molecular weight heparin was administrated within the first 24 hours following surgery until the 11 th post-operative day at the dose of $0.4 \mathrm{ml}$ of Calcic Nadroparin (3800 UI) s.c. daily. The prophylaxis was started approximately eight hours following the surgical procedure to minimize the risk of bleeding.

All the patients were gradually mobilized from the 1 st postoperative day, starting from a sitting position to autonomous ambulation as soon as the clinical condition allowed.

Daily clinical and laboratory evaluation of patient's parameters were performed (Haemoglobin, renal function, coagulation parameters). In particular, signs of VTE (such as oedema and pain at lower extremities) and of Pulmonary Embolism (PE) (dyspnoea, difficult breathing) were sought.

\section{RESULTS} mented:

Out of 500 patients, we observed and docu-

- One case of pulmonary micro-embolism

- One case of sural phlebitis

- No case of intra- or peri-operative death

- Two surgical revisions for peri-operative bleeding

- No case of significant (> $4 \mathrm{~cm}$ ) lymphocoele

- No other major complications.

In addition, based on clinical signs and symptoms, VTE was suspected in 8 patients who were assessed by pulmonary scinti-scan with radionuclides.

We treated the patients affected by microembolism or sural flebitis with prolonged heparin therapy and followed by dicumarol therapy until the 6th postoperative month.

Haemoglobin parameters, patients' age, PSA and transfusion rate (Tab 1) were compared by Student's $t$ test (7). $52.4 \%$

The percentage of transfused patients was

Cumulative use of autologous blood units was $49.5 \%$ (444 transfused units out of 896 ); we also report the use of 15 homologous blood units.

All the patients who received homologous transfusion had already received their own predeposited blood before receiving donor blood or plasma.
Two patients underwent to surgical revision for haemorrhagic problems.

No direct correlation was observed between prostate size and need for transfusion; on the contrary, a trend toward an inverse correlation was found with more blood loss in RRP done for small prostates cancer.

Statistic analysis identified as the only parameter discriminating need for transfusion was haemoglobin basal value; the data revealed that no transfusion was likely to be needed when the patient's basal haemoglobin value was higher than $14,7 \mathrm{~g} / \mathrm{dl}$ (7).

\section{DISCUSSION}

To our knowledge no information is available in the literature about the risk/benefit assessment and of the prophylaxis of VTE around major surgical interventions and, as a consequence, there is no worldwide agreement. RRP is considered a surgical procedure at high risk for venous thrombosis and thromboembolic events are considered the most devastating non surgical complication of major urologic procedures.

Because most of the epidemiological data were produced 10 to 30 years ago, it is possible that some of the available information on the risk of VTE is not applicable to present risk assessment as during the last decade many changes have occurred including new surgical techniques, the emphasis on early mobilization, and, possibly, greater use of medical and mechanical prophylaxis. All these precautions combined apparently have resulted in decreased rates of VTE over time. However, 1 to $5 \%$ of nowadays patients undergoing major urological surgery experience symptoms of VTE and fatal PE is still seen occasionally (risk </- 0.002).

Many US surgeons and physicians believe that the overall incidence of VTE among hospitalized and post-operative patients has decreased sufficiently over the past decades to a point where the incidence is too low to justify the iatrogenic risks of pharmacological prophylaxis.

Soloway et al. $(2,12)$ suggested that the incidence of VTE after RRP is decreased because of the use of mechanical compression devices and early mobilization based on the observation that the rate of VTE after RRP in patients who received heparin prophylaxis is similar to that of untreated ones. Therefore these authors concluded that routine heparin prophylaxis is not warranted. 
Geerts and Agnelli $(1,13)$ suggested another reason to avoid prophylaxis especially in surgical patients; the concern of increased risk for bleeding complications from anticoagulants. Heparin-induced thrombocytopenia is also a potential concern with the widespread use of heparin preparations. The rate of thrombocytopenia with prophylactic use of heparin is 1 to $5 \%$, and the incidence of clinically overt vascular thrombosis in postoperative patients with heparin-induced thrombocytopenia than unfractionated heparin. LMWHs are much less likely to produce heparin-induced thrombocytopenia than unfractionated heparin. The costs of thromboprophylaxis have also been used as an argument against its wider use; however, the studies addressing this issue have uniformly concluded that broad application of prophylaxis is highly cost-effective.

Probably, because VTE is most often clinically silent, its occurrence may be under-estimated as only overt cases are documented. For example, extrapolation of data from meta-analyses suggests that fatal PE occurs in 0.5 to $0.8 \%$ of unprotected patients over the age of 40 undergoing major abdominal surgery and, in many of these, the diagnosis and cause of death would not be detected. Similarly, although postoperative proximal deep venous thrombosis is present in 6 to $7 \%$ of general surgery patients, the majority do not have clinical manifestations and, therefore, would not be detected. So the physician would not be aware of a reduction in the incidence of fatal PE from 0.7 to $0.2 \%$ in his or her own practice compared with the power of a meta-analysis with the use of low-dose unfractionated Heparin (LDUH). Thus, from an individual practice perspective, it is difficult to appreciate the effectiveness of prophylaxis, whereas failures are readily apparent. In addition, bleeding complications are highly visible, not easy forgotten, and frequently attributed, inappropriately, to the use of prophylaxis.

Therefore, the need of heparinic prophylaxis in major surgery is still matter of debate (14).

The optimal start of pharmacological prophylaxis for VTE in surgical patients is unresolved issue (15).

We use pharmacological prophylaxis starting 24 hours after surgery, without any significant bleeding nor VTE in our series.

Advantages of autologous donation include prevention of transfusion-transmitted viral infections, avoidance of immunosensitization, reduction in the risk of delayed haemolytic transfusion reactions and augmentation of the blood supply. However, autologous blood transfusion is not completely exempt from risk, such as bacterial contamination; another problem frequently observed is the percentage of elimination occurring because of their expiration.

Sometimes transfusional therapy is started mainly because of "blood availability" rather than of real "blood need".

If we consider only the need of intra-operative or postoperative blood supply, our data point out that blood predeposit program is questionable when patient's preoperative haemoglobin level is higher than $14 \mathrm{mg} / \mathrm{dl}$.

But, if the routine use of autologous blood donation is matter of debate because of costs, we had to stress the protective role of haemodilution related to this procedure in the forming of VTE.

The pathophysiology of thrombosis is clear, but the identification of the precise moment of the genesis of the thrombus is still unclear; so the reasonable question is: at what time does the thrombus form? Intra operatively or later?

We stress the importance of both mechanical and pharmacological approach.

In our experience we could consider many points in preventing VTE:

- Haemodilution

- Autotransfusion

- Mechanical compression with compressive stockings or external pneumatic compression device

- Patient's surgical position

- Clipping of lymphatic vessels during lymphadenectomy

- Intra operative $\mathrm{Hb}$ value of $10 \mathrm{~g} / \mathrm{dl}$ and $\mathrm{Ht}$ value at $30-33 \%$

- Early mobilization

- LMWH prophylaxis

We stress that the time when thrombogenesis begins is not yet clearly known and as a consequence the ideal time to start prophylaxis with $\mathrm{LMWH}$ remains to be clarified. This study suggests that a safe time would be the early post-operative period that does not diminish the therapeutic benefit while decreasing the chances of peri-operative bleeding.

We give both pharmacological and mechanical devices to prevent venous thrombosis.

We use low molecular weight heparin administrated within 24 hours after surgery until 11 th day at the dose of $0.4 \mathrm{ml}$ of Calcic Nadroparin $3800 \mathrm{UI}$ s.c. daily for each patient, without increasing risk of 
thromboembolic events nor haemorrhagic events. In fact we didn't register any severe case of VTE nor PE.

We also recommended autologous predeposit, intraoperative haemodilution, long period compressive stockings, supine operative position of the patient and postoperative care with early mobilization. We consider the surgical care of clipping lymphatic vessels during lymphectomy very important to avoid the risk of compressive lymphocoele.

We think that those procedures help preventing the thromboembolic events.

Limited of the study: this is a retrospective study and there are no control patients.

\section{REFERENCES AND RECOMENDED READINGS ("of special interest, ${ }^{* *}$ of outstanding interest)}

**1. Agnelli G. Prevention of Venous thromboembolism in surgical patients. Circulation 2000; 110: IV-4 - IV-12,

**2. Koya MP, Manoharan M, Kim SS, Soloway MS. Venous thromboembolism in radical prostatectomy: is heparinoid prophylaxis warranted?. BJU Int, 2005; 96: 1019-21.

3. Borghi B, Stagni F, Bacchilega I. Blood salvage technique to avoid homologous blood transfusion in orthopaedic surgery. Internal Medicine, 2001; 9:30-35.

*4. Golash A, Collins PW, Kynaston HG et al. Venous thromboembolism prophylaxis for transurethral prostatectomy: practice among British urologist. J R Soc Med, 2002; 95:130-131.

5. Waters JH, Lee JS, Klein E, et al. Preoperative autologous donation versus cell savage in the avoidance of allogenic transfusion in patients un- dergoing radical retropubic prostatectomy. Anesth Analg, 2004; 98:537-42.

6. Hayakawa K, Sato H, Aoyagy T et al. The use of predeposited autologous blood transfusion for radical prostatectomy and total cystectomy. Nippon Hinyokika Gakkai Zasshi, 1999; 90(4):496-501.

*7. Tramacere P, Tomasiello D, Besana S, et al. Preoperative autologous blood donation in prostate surgery. Blood Transfus, 2005; 3: 194-206.

8. Borghi B, Casati A. Incidence and risk factors for allogenic blood transfusion during major joint replacement using an integrated autotransfusion regimen. The Rizzoli Study Group in Orthopaedic Anaesthesia.. Eur J Anaesthesiol, 2000; 17(7):411-7.

9. Canterbury TD, Wheeler WE, Scott-Conner CE. Effect of the lithotomy position on arterial blood flow in the lower extremities. W V Med J, 1992; 88(3):100-1.

10. Walsh PC. Anatomic radical prostatectomy: evolution of the surgical technique. J Urol, 1998; 160 (6 Pt2): 2418-24.

11. Lieskovsky G, Skinner DG, Weisenburger T. Pelvic lymphadenectomy in the management of carcinoma of the prostate. J Urol, 1980; 124(5):6358.

**12. Soloway MS. Re: The use of enoxaparin to prevent venous thromboembolism in patients undergoing radical retropubic prostatectomy: feasibility and utility. Int Braz J Urol, 2007; 33(4):565-6.

13. Geerts WH, Heit JA, Clagett GP et al. Prevention of venous thromboembolism. Chest, 2001; 119132S-175S

**14. Grasso M, Torelli F, Blanco S et al. Venous thromboembolism in radical prostatectomy: is postoperative heparinoid prophylaxis recommended?. Urology, 2007; Sept; Vol.70 Suppl 3A, p.138.

15. Kibel AS, Creager MA, Goldhaber SZ, et al. Late venous thromboembolic disease after radical prostatectomy: effect of risk factors, warfarin and early discharge. J Urol, 1997; 158(6):2211-5. 